\title{
Effects of Interface Damage Resulting from the Separation of Layered Strata on Bolt Anchoring Systems
}

\author{
Xiaowei Feng, Nong Zhang, and Chuangxin Lv \\ School of Mines, Key Laboratory of Deep Coal Resource Mining, Ministry of Education, China University of Mining and Technology, \\ Xuzhou 221116, China \\ Correspondence should be addressed to Nong Zhang; zhangnong@126.com
}

Received 14 September 2015; Revised 2 December 2015; Accepted 14 December 2015

Academic Editor: Salvatore Russo

Copyright (C) 2016 Xiaowei Feng et al. This is an open access article distributed under the Creative Commons Attribution License, which permits unrestricted use, distribution, and reproduction in any medium, provided the original work is properly cited.

Layered strata occurrence is frequently seen in underground constructions, the man-made excavation is thus easy to cause separation between neighboring strata. The sudden and unexpected occurrence of separation will induce significant shock wave and vibration to relative bolting system that initially holds the normal working space for underground production. The bolting system is extremely sensitive to this shock and is easily weakened or damaged. By examining the locations of strata separation and the extent of damage along an anchoring interface, this paper investigates the factors that influence the support strength of anchoring system. The results show that the support strength of a bolt is independent of the separation location if the resin-rock interface is intact. The opposite is the case if the separation width between the neighboring strata exceeds the ultimate critical value, which induces damage along the interface. In this case, the support strength increases exponentially as the separation increases. Separation at the free loading end dramatically decreases the support strength. However, this decrease is mitigated if the separation is located in the middle of the anchoring body or at the loading end. These results are then calibrated and verified in a laboratory test.

\section{Introduction}

Bolts are utilized to transfer tension into the surrounding ground and thus generate compression effects in the surrounding strata. Because they provide both active support and reinforcement, bolts have been frequently used in collieries in China since the mid-1990s, and roof bolting has been the primary roof support method for underground coal mines since the early 1970s in the US [1]. Due to these advantageous properties, which are especially beneficial for supporting layered roof strata, bolts provide better reinforcement than other measures, such as props, U-shaped supports, and sprayed concrete [2-6]. Unfortunately, these benefits may be less significant in engineering practice, where layered strata are negatively affected by factors such as the ground stress, rock properties and structure, mining speed, and bolt parameters, which frequently cause strata to separate $[7,8]$. Figure 1 presents an example of layered strata in the Zhuji Mine of Huainan Mining Group, China, Figure 1(b) is the enlarged view of polygon in Figure 1(a). This paper investigates the influence of this separation on the originally installed bolt anchoring system and the system under loading.

The prevailing concept for the design of bolts is the coupling relationship of the bolt-resin interface or the resinrock interface, which is especially important for supporting galleries in collieries [9]. The magnitude of the shear stress along these two interfaces are dependent on the pretension load applied on the bolt, and the relative displacement between the various neighboring media is also dependent on this load. Hence, it is believed that the anchoring failure of bolts is mainly caused by a reduction in the bond stress along these interfaces [10]. The bond strength is influenced by adhesion, friction, and mechanical interlocking because of the rough microscale interface [11]. Here, $\tau_{1}$ represents the ultimate shear stress along the bolt-resin interface, whereas $\tau_{2}$ represents the ultimate shear stress along the resin-rock interface. Thus, the following coupling relationships can be defined:

(i) $\tau_{1}>\tau_{2}$ : the preferential failure interface is the resinrock interface. 


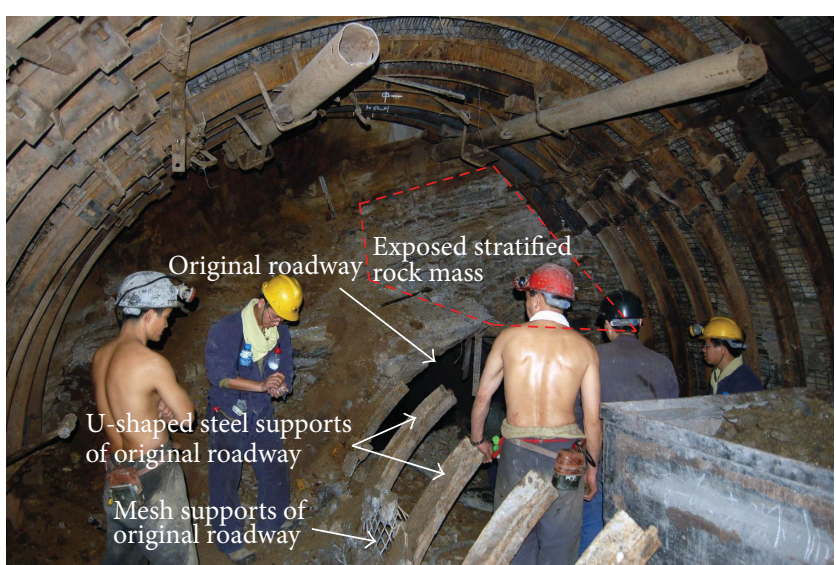

(a)

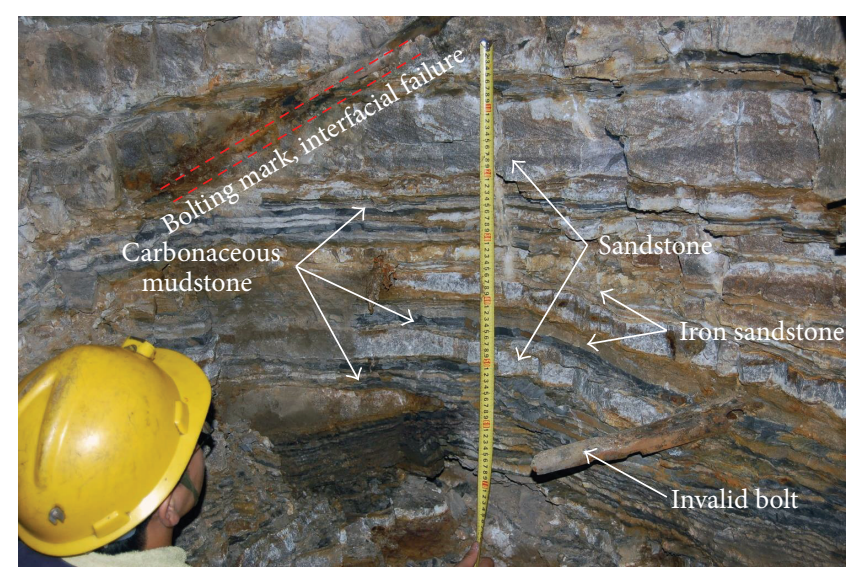

(b)

FIGURE 1: Photos of supporting failure case in Zhuji Mine of Huainan Mining Group. (a) Overview of supporting failure under layered strata occurrence and (b) enlarged view of red dashed polygon in (a), showing bolting failure example.

(ii) $\tau_{2}>\tau_{1}$ : the preferential failure interface is the boltresin interface.

This interface failure problem has not been definitively solved, and no universally accepted criteria have been developed. However, bolt-resin interface is generally considered to be weaker than resin-rock interface in underground engineering at shallow depths, and the bolt-resin interface dominating bolting failure is more likely to be seen under the circumstance. Several valuable conclusions concerning boltresin interface failure can be referred based on some excellent studies [12-15]. From another perspective, Moosavi et al. and Benmokrane et al. studied the resin-rock interface and bond failures along this interface that occur prior to failure along the bolt-resin interface $[16,17]$. Using the actual performance of bolting interface under different conditions reported in these studies, we develop a simplified scheme for obtaining analytical results, and we also design a lab test to calibrate the theoretical results. Surrounding rock mass in coal-bearing formations is mainly specified by soft mechanical properties, and it is reasonable to assume that the ultimate shear stress along the resin-rock interface is lower than that along the bolt-resin interface under such condition; this assumption is supported by the large number of support bolt failures that have occurred in coal mine roadway supporting practices. The research presented in this paper focuses on the resinrock interface, which is simply referred to as the "interface"; hence, the bolt and resin can be treated as being tightly bonded and are referred to as the "anchoring body." Based on this criterion, this paper presents research on the shear stress distribution along the interface and the evolution of the interface damage under the influence of strata separation.

\section{Shear Stress Distribution along the Interface}

2.1. Development of the Equations for the Shear Stress along Intact Interface. It has been testified that the shear stress along the interface is exponentially distributed, and it is doubly affected by the initial pretension force and the elastic modulus ratio between the anchoring body and the rock mass [18]. Hawkers further developed the equation for the interface shear stress, which is

$$
\tau(x)=\tau e^{-k x / d}
$$

where $\tau(x)$ is the shear stress at a distance $x$ from the loading end; $\tau$ is the shear stress at the loading end $(x=0)$; $d$ is the borehole diameter, which is equal to the diameter of the anchoring body; and $k$ is a constant that is correlated with the principal stress and the interfacial bond stress.

Farmer developed the following widely used equation for the shear stress [18], which is a refined form of (1):

$$
\tau(x)=\frac{\alpha}{2} \sigma e^{-2 \alpha(x / d)},
$$

where

$$
\begin{aligned}
& \alpha^{2}=\frac{2 G_{r} G_{\mathrm{re}}}{E_{b}\left[G_{r} \ln \left(d / d_{b}\right)+G_{\mathrm{re}} \ln \left(d_{0} / d\right)\right]}, \\
& G_{r}=\frac{E_{r}}{2\left(1+v_{r}\right)} ; G_{\mathrm{re}}=\frac{E_{\mathrm{re}}}{2\left(1+v_{\mathrm{re}}\right)},
\end{aligned}
$$

where $\sigma$ is the axial stress at the loading end; $E_{b}, E_{r}$, and $E_{\text {re }}$ are the elasticity moduli of the bolt, rock mass, and resin, respectively; $v_{r}$ and $\nu_{\text {re }}$ are the Poisson's ratios of the rock mass and resin, respectively; $d_{0}$ is the influencing diameter on the surface of the rock mass that is induced by the bolting; and $d_{b}$ is the diameter of the bolt.

2.2. Shear Stress Distribution along Damaged Interface. Three stages of evolution are distinguished based on research by He et al. and You et al.: the elastic stage, slippage stage, and decoupling stage $[19,20]$. Assuming that the interface is in its original intact state, the shear stress along the interface decreases exponentially with increasing distance from the loading end [21]. However, the stress distribution is different if the interface is already damaged. The damaged section 


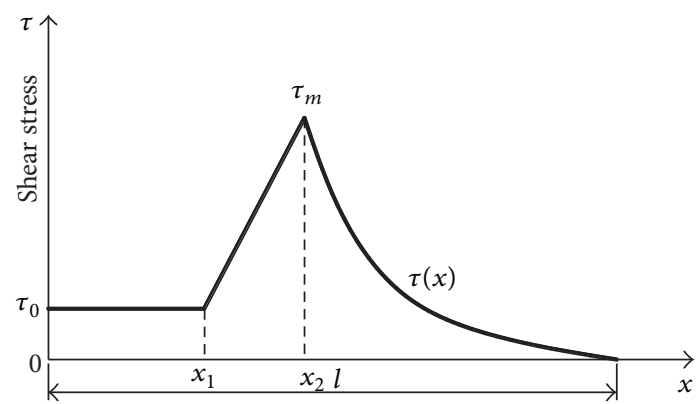

FIgURE 2: Typical shear stress distribution along a partially damaged interface.

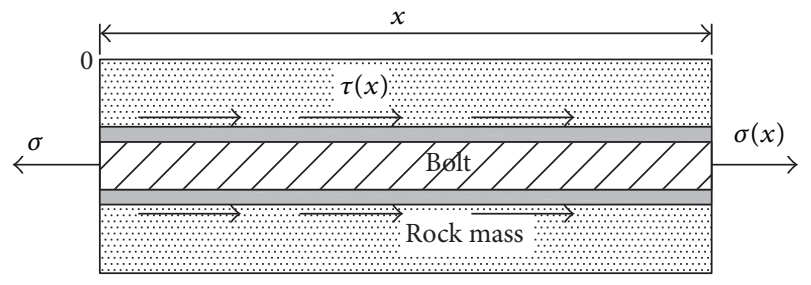

FIGURE 3: Micromechanical model of an anchoring body.

along the interface will extend from the near end (close to the bolt-hole collar) to the far end (near the bottom of the bolt-hole). These three stages form a continuous sequence from the original intact state to the final damaged state. Figure 2 schematically illustrates a typical shear stress distribution along a partially damaged interface [20], where $\tau_{0}$ is the residual shear stress of the decoupling section, $\tau_{m}$ is the ultimate shear stress that the intact interface can sustain, and $\tau(x)$ is the shear stress of the elastic section. The characteristics of each section are described as follows.

(1) The elastic stage corresponds to section $\left(x_{2}, l\right)$ in Figure 2, where $l$ is the total length of the anchoring body. For full-length anchoring, $l$ is equal to the difference between the total length of the bolt and the length of the exposed portion of the bolt. An anchoring force applied by tension machine on the exposed portion can transfer supporting force to peripheral rock mass through the equipped face plate; then a friction force can be created all along the interface (between the rock mass and the anchoring body) of the embedded portion of the bolt; this procedure has multiple strengthening effects that counteract the deformation of the surrounding rock [22]. During the initial stage of the damage evolution, the procedure prevents damage caused by the initial deformation of the rock or coal. Hence, the shear stress has an exponential distribution and decays simultaneously in the direction of the free loading end (near the bolt-hole bottom); this is the so-called elastic stage. Considering the static equilibrium between the interfacial shear stress and the axial stress in the anchoring body, a microanalytical segment is schematically illustrated in Figure 3, and the axial stress of the anchoring body can be calculated as follows.
According to the horizontal static equilibrium in Figure 3, (4) can be expressed as

$$
\sigma(x)+\frac{\pi d \int_{0}^{x} \tau(x) d x}{A}-\sigma=0 .
$$

By combining (2) and (4), $\sigma(x)$ can be written as

$$
\sigma(x)=\sigma e^{-2 \alpha(x / d)}=\frac{2}{\alpha} \tau(x),
$$

where $A$ is the cross-sectional area of the anchoring body and $A=\left(\pi d^{2}\right) / 4$.

(2) The slippage stage corresponds to section $\left(x_{1}, x_{2}\right)$ in Figure 2. Damage occurs along the interface if the deformation of the surrounding rock exceeds the ultimate bearing strength of the anchoring system or, in other words, it surpasses the ultimate shear stress that initially sustains an elastic state. However, some resistance remains at the interface, and this resistance can counteract certain amount of the deformation. This transitional process or evolution is the so-called slippage stage.

(3) The decoupling stage corresponds to section $\left(0, x_{1}\right)$ in Figure 2. This stage follows the slippage stage. The decoupling stage occurs due to the continuous deformation of the rock mass. In this stage, the relative displacement between the rock and the anchoring interface exceeds the ultimate bond displacement between them, the bonding effects along the interface disappear, and the relative sliding between rock and resin becomes more obvious. The interface dramatically expands during this process on account of the dilation and crack initiation of resin; the expansion effects will then exert an extrusion force on the interface and generate a constant friction force along the interface.

The different stages of Figure 2 that correspond to the different states of shear stress and axial stress are associated with the following equations, which are used in the subsequent analysis.

(a) Decoupling Stage. By combining Figure 2 and (4), (6) can be obtained as

$$
\begin{aligned}
& \tau(x)=\tau_{0}, \\
& \sigma(x)=\sigma-\frac{4 \tau_{0} x}{d}, \\
& \quad 0 \leq x \leq x_{1} .
\end{aligned}
$$

(b) Slippage Stage. Using the same methodology, (7) can be expressed as

$$
\begin{aligned}
& \tau(x)=\tau_{0}+\frac{\tau_{m}-\tau_{0}}{\Delta}\left(x-x_{1}\right), \\
& \sigma(x)=\sigma-\frac{2}{d}\left[2 \tau_{0} x-\frac{\tau_{m}-\tau_{0}}{\Delta}\left(x-x_{1}\right)^{2}\right], \\
& x_{1} \leq x \leq x_{2},
\end{aligned}
$$

where $\Delta=x_{2}-x_{1}$. 
(c) Elastic Stage. The following equations are derived from (2), (4), (5), and (1):

$$
\begin{gathered}
\tau(x)=\tau_{m} e^{-2 \alpha\left(\left(x-x_{2}\right) / d\right)}, \\
\sigma(x)=\frac{2}{\alpha} \tau_{m} e^{-2 \alpha\left(\left(x-x_{2}\right) / d\right)},
\end{gathered}
$$

$$
x_{2} \leq x \leq l
$$

Figure 2 shows that the curve is continuous at $x=x_{2}$; thus, (7) and (8) can be combined, and if the right sides of the lower equations in (7) and (8) are equivalent, the following equation for $x_{2}$ can be obtained:

$$
x_{2}=\frac{d}{4 \tau_{0}}\left[\sigma-\frac{2 \tau_{m}}{\alpha}+\frac{2}{d}\left(\tau_{m}-\tau_{0}\right) \Delta\right] .
$$

\section{Impact of Strata Separation on the Shear Stress Distribution of the Interface}

3.1. Strata Separation under an Intact Interface. Assume that two neighboring layers in the roof strata separate and that a bolt just passes through these layers. Based on the analysis presented in Section 2, the interfacial bond stress will change. It is worth noting that this kind of separation is different from that of joints with confined lateral sides [23, 24]. This is schematically illustrated in Figure 4, where Figure 4(b) is a detailed view of the area outlined by the green box in Figure 4(a). If the shear stress at the interface is less than the ultimate strength of the interface, no damage occurs, and the bilateral stress distributions on the separation are in an early elastic state, and the maximum shear stresses for upper section and lower section also equal to each other [25]. Nevertheless, the intact elastic state will transform into the slippage state or even the decoupling state if the separation continues to expand. To obtain the ultimate critical width of separation before the transformation/damage occurs, assume that the ultimate shear stress at the edge of the separation for this critical situation is $\tau_{m}$, as indicated in Figure 4.

3.1.1. Ultimate Width Variation as the Separation Locations Change. Assuming that no damage has occurred previously, the shear stress distribution varies along the separation. The shear stresses at the edge of the separation reach a maximum and then decrease exponentially in both directions, as shown in Figure 4(b).

Let the center of the separation be the origin of the coordinate axis, let $\tau_{m}$ be the ultimate shear stress, and let $\sigma_{b 0}$ be the maximum axial stress. Based on (5), $\sigma_{b 0}$ can be expressed as

$$
\sigma_{b 0}=\frac{2 \tau_{m}}{\alpha}
$$

Equation (10) defines the maximum axial stress that the intact interface can sustain. The corresponding maximum width of the separation $\delta_{J \max }$ can be written as

$$
\delta_{J \max }=\delta_{1}+\delta_{2}=\frac{1}{E_{c}} \int_{0}^{l_{1}} \sigma(x) d x+\frac{1}{E_{c}} \int_{0}^{l_{2}} \sigma(x) d x,
$$

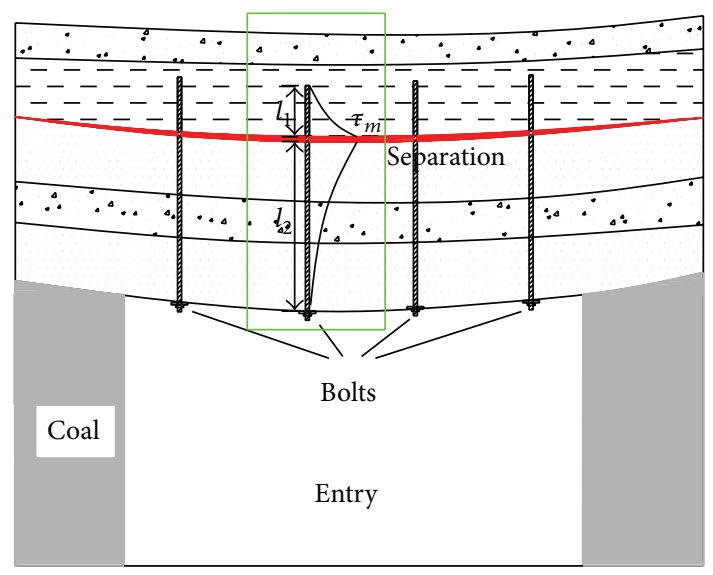

(a)

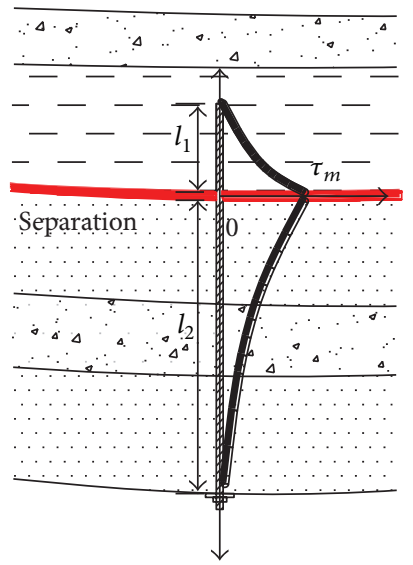

(b)

FIGURE 4: Schematic illustration of the shear stress distribution along bonding interface with separation (without interfacial damage).

where $E_{c}$ can be rewritten as [26]

$$
E_{c}=E_{b}\left(\frac{d_{b}}{d}\right)^{2}+E_{\mathrm{re}}\left(1-\frac{d_{b}^{2}}{d^{2}}\right)
$$

where $\delta_{1}$ is the width of the separation above the origin, which is caused by the elongation of segment $l_{1}$ in Figure 4(b), and $\delta_{2}$ is the width of the separation below the origin, which is caused by the elongation of segment $l_{2}$. The total width of the separation is equal to the sum of $\delta_{1}$ and $\delta_{2} . E_{c}$ is the composite Young modulus of the bolt and resin or the composite anchoring body.

It is worth noting that the diameter of the anchoring body is negligible compared with its length and is equal to that of the bolt-hole; that is, $l \gg d$. The bolts used in coal mine applications are generally M24- $\$ 22-2800 \mathrm{~mm}$ (with diameter $22 \mathrm{~mm}$ and length $2800 \mathrm{~mm}$ ) or M22-Ф20-2500 mm (with diameter $20 \mathrm{~mm}$ and length $2500 \mathrm{~mm}$ ), which are consistent 
with the simplification described above. Equation (11) can be rewritten as

$$
\delta_{\text {Jmax }}=\frac{d \sigma}{E_{c} \alpha} .
$$

Equation (13) shows that $l_{1}$ and $l_{2}$ are not affected by variations of $\delta_{J \max }$, which indicates that although separation occurs in layered strata during mining, the maximum separation width that the anchoring system can sustain remains constant as long as no damage occurs along the interface. In addition, the maximum separation is only slightly affected by the locations of the separation.

\subsection{Shear Stress Distribution of a Damaged Interface with} Strata Separation. The ultimate width $\delta_{J \max }$ is the maximum width that an intact interface can sustain; however, the intact elastic coupling relationship will break down if the overlarge deformation of the rock mass makes the separation width surpass the ultimate width, and then the initially intact interface will be damaged; this process is also called debonding. The damage sequentially evolves and progresses through the elastic, slippage, and decoupling stages. Different with the intact state illustrated in Section 3.1.1, the shear stress distribution along the interface varies with the separation locations. The following sections will analyze these principles.

3.2.1. Separation at the Free Loading End. Generally speaking, bolts have to be strong enough to sustain the dead weight of the loose blocks because of the hanging effects of bolting theory [27], and the free loading end of a bolt is the end that is closest to the bolt-hole bottom. If the separation occurs in this area, then, according to the hanging bolt theory of layered strata developed by Panek, most of the weight of the rock between the bolt collar and the separation is supported by the interfacial bonding force above the separation [28]. Under these conditions, the incipient intact anchoring body is asymmetrically divided into a relatively short upper segment and a relatively long lower segment. Assuming that the shear stress will exceed the ultimate value $\tau_{m}$ at some point due to overlarge rock deformation, the relatively short upper segment will then progress directly to the decoupling state from its initial elastic state and skip the intermediate slippage state. This is caused by the relatively short length and the relatively large load of the upper interface; thus, the length is not sufficient for the detailed evolution. The lower interface, however, is different; the longer interface and different bearing load properties allow for a detailed dynamic evolution from the elastic stage to the slippage stage to the decoupling stage. The aforementioned evolution process will be calibrated by experimental verification in Section 4 . The overall shear stress distribution is illustrated in Figure 5 [29].

Figure 5 clearly shows that the short upper interface has progressed into the decoupling state due to the large axial force, and the shear stress along this range of interface maintains a constant value $\tau_{0}$. The long lower interface is also partially damaged because of the large amount of rock deformation, and the location of the peak shear stress in the elastic stage shifts down to $x_{2}$. The slippage segment and

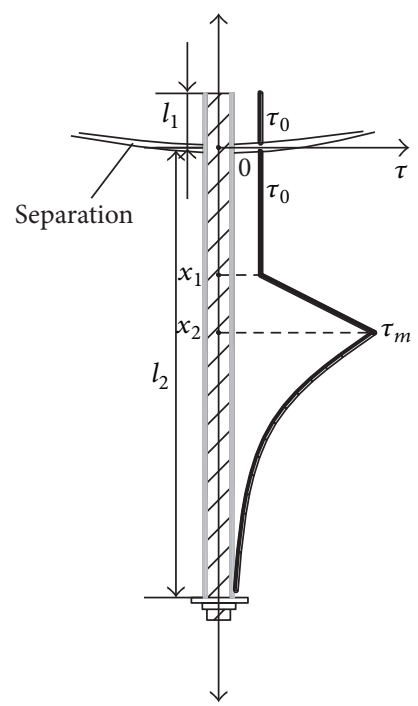

FIGURE 5: Shear stress distribution of the damaged interface when separation occurs at the free loading end.

the decoupling segment are adjacent to each other. The total separation width is the sum of the elongations of the upper and lower anchoring bodies, which can be written as

$$
\delta_{J a}=\int \varepsilon d x=\frac{1}{E_{c}} \int \sigma(x) d x,
$$

where the elongation of the upper body is

$$
\begin{aligned}
\delta_{1 a} & =\frac{1}{E_{c}} \int_{0}^{l_{1}} \sigma(x) d x=\frac{1}{E_{c}} \int_{0}^{l_{1}}\left(\sigma-\frac{4 \tau_{0} x}{d}\right) d x \\
& =\frac{1}{E_{c}} l_{1}\left(\sigma-\frac{2 \tau_{0} l_{1}}{d}\right) .
\end{aligned}
$$

The elongation of the lower body is the sum of the elastic, slippage, and decoupling segments. By combining (6) (9), the following equation can be obtained:

$$
\begin{aligned}
\delta_{2 a} & =\frac{1}{E_{c}}\left[\int_{0}^{x_{1}} \sigma(x) d x+\int_{x_{1}}^{x_{2}} \sigma(x) d x\right. \\
& \left.+\int_{x_{2}}^{l_{2}} \sigma(x) d x\right]=\frac{1}{E_{c}}\left\{\int_{0}^{x_{1}}\left(\sigma-\frac{4 \tau_{0} x}{d}\right) d x\right. \\
& +\int_{x_{1}}^{x_{2}}\left\{\sigma-\frac{2}{d}\left[2 \tau_{0} x-\frac{\tau_{m}-\tau_{0}}{\Delta}\left(x-x_{1}\right)^{2}\right]\right\} d x \\
& \left.+\int_{x_{2}}^{l_{2}} \frac{2}{\alpha} \tau_{m} e^{-2 \alpha\left(\left(x-x_{2}\right) / d\right)} d x\right\}=\frac{1}{E_{c}}\left\{x_{1}(\sigma\right. \\
& \left.-\frac{2 \tau_{0} x_{1}}{d}\right)+\Delta\left[\sigma-\frac{2 \tau_{0}}{d}\left(x_{1}+x_{2}\right)\right. \\
& \left.\left.+\frac{2\left(\tau_{m}-\tau_{0}\right) \Delta}{3 d}\right]+\left[-\frac{d \tau_{m}}{\alpha^{2}}\left(e^{-2 \alpha\left(\left(l_{2}-x_{2}\right) / d\right)}-1\right)\right]\right\} .
\end{aligned}
$$


TABLE 1: Parameters of the anchoring system and surrounding rock mass* .

\begin{tabular}{lccccccc}
\hline$E_{b} / \mathrm{MPa}$ & $E_{\mathrm{re}} / \mathrm{MPa}$ & $E_{r} / \mathrm{MPa}$ & $E_{c} / \mathrm{MPa}$ & $l / \mathrm{m}$ & $d / \mathrm{mm}$ & $d_{b} / \mathrm{mm}$ & $\Delta / \mathrm{m}$ \\
\hline $3.00 \times 10^{5}$ & $1.60 \times 10^{4}$ & $2.50 \times 10^{4}$ & $5.97 \times 10^{4}$ & 2.80 & 34.00 & 22.00 & 0.1 \\
\hline$d_{0} / \mathrm{m}$ & $\tau_{0} / \mathrm{MPa}$ & $\tau_{m} / \mathrm{MPa}$ & $G_{r} / \mathrm{MPa}$ & $G_{\mathrm{re}} / \mathrm{MPa}$ & $\nu_{r}$ & $\nu_{\mathrm{re}}$ \\
\hline 0.80 & 0.8 & 8.0 & $0.96 \times 10^{4}$ & $0.57 \times 10^{4}$ & 0.30 & 0.40 & 4.04 \\
\hline
\end{tabular}

${ }^{*}$ Face 1111(1) of the Zhuji Mine, Huainan Mining Group, China.

Thus,

$$
\begin{aligned}
\delta_{J a} & =\delta_{1 a}+\delta_{2 a}=\frac{1}{E_{c}}\left\{l_{1}\left(\sigma-\frac{2 \tau_{0} l_{1}}{d}\right)\right. \\
& +x_{1}\left(\sigma-\frac{2 \tau_{0} x_{1}}{d}\right) \\
& +\Delta\left[\sigma-\frac{2 \tau_{0}}{d}\left(x_{1}+x_{2}\right)+\frac{2\left(\tau_{m}-\tau_{0}\right) \Delta}{3 d}\right] \\
& \left.+\left[-\frac{d \tau_{m}}{\alpha^{2}}\left(e^{-2 \alpha\left(\left(l_{2}-x_{2}\right) / d\right)}-1\right)\right]\right\} .
\end{aligned}
$$

Note that, during the initial stage of damage, $\left(l_{2}-x_{2}\right) \gg d$. Thus, the last item in the braces in (17) can be simplified as $d \tau_{m} / \alpha^{2}$, and (17) can be rewritten as

$$
\begin{aligned}
\delta_{J a} & =\delta_{1 a}+\delta_{2 a}=\frac{1}{E_{c}}\left\{l_{1}\left(\sigma-\frac{2 \tau_{0} l_{1}}{d}\right)\right. \\
& +x_{1}\left(\sigma-\frac{2 \tau_{0} x_{1}}{d}\right) \\
& \left.+\Delta\left[\sigma-\frac{2 \tau_{0}}{d}\left(x_{1}+x_{2}\right)+\frac{2\left(\tau_{m}-\tau_{0}\right) \Delta}{3 d}\right]+\frac{d \tau_{m}}{\alpha^{2}}\right\} .
\end{aligned}
$$

If the damage has already extended across most of the lower interface, then $l_{2} \approx x_{2}$. Therefore, the last item can be considered zero, and (17) becomes

$$
\begin{aligned}
\delta_{J a} & =\delta_{1 a}+\delta_{2 a}=\frac{1}{E_{c}}\left\{l_{1}\left(\sigma-\frac{2 \tau_{0} l_{1}}{d}\right)\right. \\
& +x_{1}\left(\sigma-\frac{2 \tau_{0} x_{1}}{d}\right) \\
& \left.+\Delta\left[\sigma-\frac{2 \tau_{0}}{d}\left(x_{1}+x_{2}\right)+\frac{2\left(\tau_{m}-\tau_{0}\right) \Delta}{3 d}\right]\right\} .
\end{aligned}
$$

Based on (17) (19) and to further analyze the relationship among the bolt support strength, strata separation width, and decoupling length, we refer to the bolt support parameters and roof strata parameters of the headentry in face 1111(1), Zhuji Mine of Huainan Mining Group, China. These parameters are shown in Table 1, and substitute them into (19), then the data were processed and plotted using MATLAB software, and the results are shown in Figure 6.

Figure 6 shows that damage can occur even with a relatively small separation width $\delta_{J a}$, and the interface damage extends in both directions from the separation point. This conclusion is consistent with the results of Stillborg

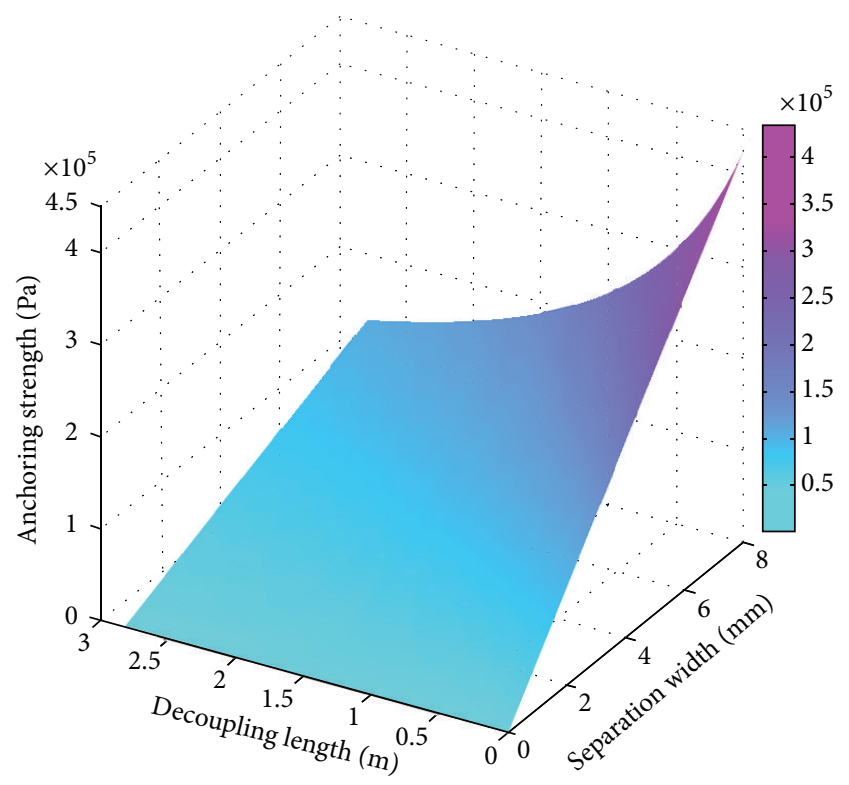

FIGURE 6: Relationship of the bolt support strength versus strata separation width and the bolt support strength versus decoupling length (the separation is located at the free loading end).

and Bawden [30, 31]. Moreover, the support strength of the anchoring system increases dramatically with increasing separation width to a maximum strength of $0.43 \mathrm{MPa}$. This value is slightly conservative based on the principle that the reinforcement strength of the roof in deep colliery applications should be no less than 0.4 MPa [32].

The hanging effects mainly depend on the free loading end; damage in this area will dramatically influence the overall stability of the anchoring system. Consequently, the maximum strength of $0.43 \mathrm{MPa}$ is only slightly higher than the suggested value of $0.4 \mathrm{MPa}$. The maximum value may be less than this limit if the separation is in the initial stage. Hence, the bolt may not provide the required reinforcement.

The relationship between the decoupling length $x_{1}$ and the support strength is discussed below. The axial stress decreases exponentially as either $x_{1}$ or the decoupling range increases. In China, coal bolts are typically $2500 \mathrm{~mm}$ or $2800 \mathrm{~mm}$ long; thus, the minimum support strength occurs as $x_{1}$ approaches $3 \mathrm{~m}$, and, in the most extreme case, the minimum strength does not reach zero, even when the entire interface is damaged or decoupled ( $3 \mathrm{~m}$ versus $2500 \mathrm{~mm}$ or $2800 \mathrm{~mm}$ ). This indicates that the rough interface and the extrusion force (due to dilation of the resin during damage) are capable of creating a constant friction force along 
the anchoring interface, which will provide some support; however, the strength is much lower than the suggested support strength of $0.4 \mathrm{MPa}$ and is thus not recommended.

Additionally, the last item of (18), $d \tau_{m} / \alpha^{2}$, has little impact on the overall fitting curve and is thus negligible compared with the total support strength of the anchoring system. This demonstrates that the elongation of the anchoring body caused by separation is mainly a result of the slippage and decoupling sections. The elastic section adds only an infinitesimal amount of elongation.

3.2.2. Separation in the Middle of the Anchoring Body. Similar to the case described above, when the separation occurs in the middle of the anchoring body, damage is generated as the separation width reaches the ultimate critical value $\delta_{\text {Jmax }}$ that the interface can sustain. The stress distribution from the separation is approximately symmetric under these conditions; hence, both sides are sufficiently long to sequentially pass through the elastic stage, slippage stage, and decoupling stage. The ultimate stress due to the separation simultaneously moves toward the loading end and the free loading end. The stress distribution of the total interface damage is schematically illustrated in Figure 7 [29].

Under these conditions, the separation width can be calculated by doubling one side because of the approximate symmetry. Based on (6) to (9), the total width can be expressed as

$$
\begin{aligned}
\delta_{J b} & =\delta_{1 b}+\delta_{2 b}=2 \delta_{1 b}=\frac{2}{E_{c}}\left[\int_{0}^{x_{1}} \sigma(x) d x\right. \\
& \left.+\int_{x_{1}}^{x_{2}} \sigma(x) d x+\int_{x_{2}}^{l_{1}} \sigma(x) d x\right] \\
& =\frac{2}{E_{c}}\left\{\int_{0}^{x_{1}}\left(\sigma-\frac{4 \tau_{0} x}{d}\right) d x\right. \\
& +\int_{x_{1}}^{x_{2}}\left\{\sigma-\frac{2}{d}\left[2 \tau_{0} x-\frac{\tau_{m}-\tau_{0}}{\Delta}\left(x-x_{1}\right)^{2}\right]\right\} d x \\
& \left.+\int_{x_{2}}^{l_{1}} \frac{2}{\alpha} \tau_{m} e^{-2 \alpha\left(\left(x-x_{2}\right) / d\right)} d x\right\}=\frac{2}{E_{c}}\left\{x_{1}(\sigma\right. \\
& \left.-\frac{2 \tau_{0} x_{1}}{d}\right)+\Delta\left[\sigma-\frac{2 \tau_{0}}{d}\left(x_{1}+x_{2}\right)\right. \\
& \left.\left.+\frac{2\left(\tau_{m}-\tau_{0}\right) \Delta}{3 d}\right]+\left[-\frac{d \tau_{m}}{\alpha^{2}}\left(e^{-2 \alpha\left(\left(l_{1}-x_{2}\right) / d\right)}-1\right)\right]\right\} .
\end{aligned}
$$

By substituting the relevant parameters from Table 1 into (20), the three-dimensional curve can be calculated. This curve is plotted in Figure 8.

As shown in Figure 8, an increase in the separation width $\delta_{J b}$ increases the support strength. The maximum support strength of $2.39 \mathrm{MPa}$ is significantly greater than that obtained when separation occurs at the free loading end $(0.43 \mathrm{MPa})$. Hence, separation in the middle of the anchoring system is much more stable and durable than separation at the free loading end because separation at the free loading

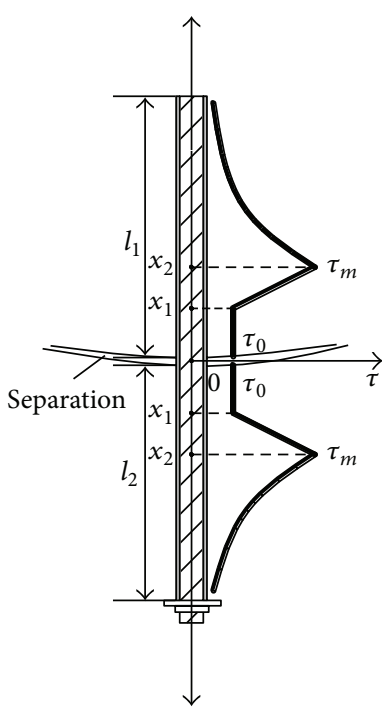

FIGURE 7: Shear stress distribution of the damaged interface when separation occurs in the middle of the anchoring body.

end will dramatically weaken the hanging effects of the bolt, whereas the free loading end can be partially protected when separation is located in the middle.

Similar to Figure 7, the support strength decreases exponentially with the initial increase of the decoupling length $x_{1}$ but with a steeper gradient. When the decoupling length $x_{1}$ exceeds $1.2 \mathrm{~m}$, the support strength is not sensitive to an additional increase of the decoupling length, and the reduction of support strength also ceases. If the simulated bolt is $2800 \mathrm{~mm}$ long, the total separation in the decoupling section can reach more than $2.4 \mathrm{~m}$ when $x_{1}$ is greater than $1.2 \mathrm{~m}$, which accounts for at least $86 \%$ of the overall length of the bolt. As described above, the elastic section has a very small effect on the variation of the axial stress; thus, most of the interface is in the decoupling state, and the rest is in the slippage state, which is small. Finally, the stress over most of the interface is a constant value $\tau_{0}$, which also explains why the decreasing gradient of anchoring strength changes slightly when the decoupling length exceeds $1.2 \mathrm{~m}$, as can be seen in Figure 7.

3.2.3. Separation at the Loading End. The loading end is the area closest to the bolt-hole collar. If the separation occurs in this area, the vertical height upper rock mass is much larger than that of the lower mass; namely, $l_{1} \gg l_{2}$. If the separation width exceeds the ultimate critical width $\delta_{\max }$ that the anchoring system can sustain, the upper interface is more likely to be damaged, and the separation induces an asymmetric shear stress distribution. The maximum shear stress is much lower on the lower interface than on the upper interface, which may be easier to understand if we treat the lower rock mass and face plate as a single unit that experiences the same effects as the original face plate. Consequently, the lower anchoring body will maintain its original elastic state even if the upper body is already in the slippage state or decoupling state [30]. Simultaneously, the 


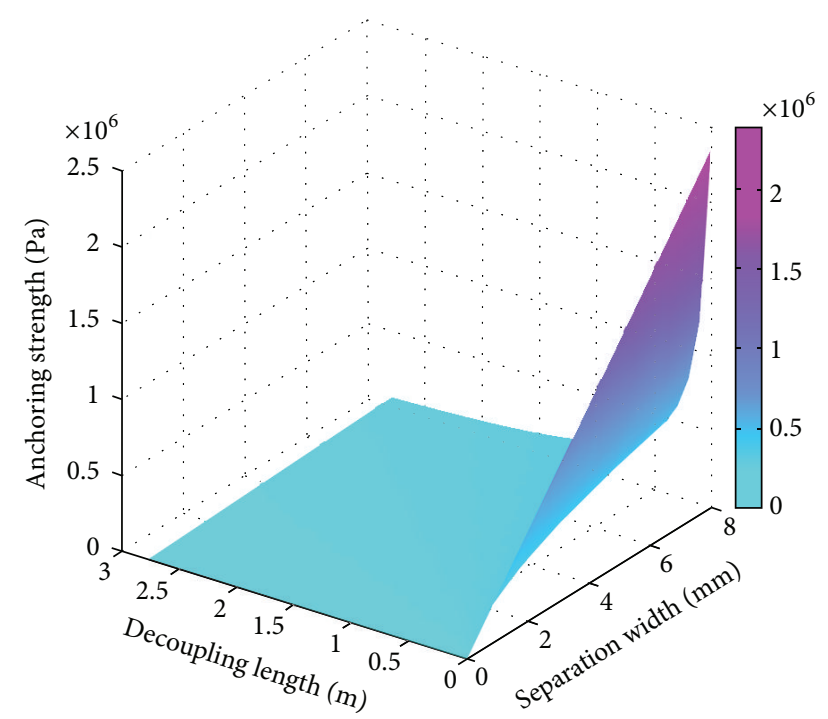

FIGURE 8: Relationship of the bolt support strength versus strata separation width and the bolt support strength versus decoupling length (the separation is located in the middle).

maximum shear stress of the lower anchoring body may have not reached the ultimate damaged stress $\tau_{m}$. As mentioned previously, the last item of (18) can be ignored; thus, the elongation of the lower anchoring body also can be ignored.

Figure 9 shows a typical stress distribution for the initial conditions, where the upper states are composed of the decoupling section $\left(0, x_{1}\right)$, the slippage section $\left(x_{1}, x_{2}\right)$, and the elastic section $\left(x_{2}, l_{1}\right)$ from bottom to top. The lower portion is solely in the elastic state.

The separation width can be expressed as

$$
\begin{aligned}
\delta_{J c} & =\delta_{1 c}+\delta_{2 c}=\delta_{1 c}+0=\frac{1}{E_{c}}\left[\int_{0}^{x_{1}} \sigma(x) d x\right. \\
& \left.+\int_{x_{1}}^{x_{2}} \sigma(x) d x+\int_{x_{2}}^{l_{1}} \sigma(x) d x\right] \\
& =\frac{1}{E_{c}}\left\{\int_{0}^{x_{1}}\left(\sigma-\frac{4 \tau_{0} x}{d}\right) d x\right. \\
& +\int_{x_{1}}^{x_{2}}\left\{\sigma-\frac{2}{d}\left[2 \tau_{0} x-\frac{\tau_{m}-\tau_{0}}{\Delta}\left(x-x_{1}\right)^{2}\right]\right\} d x \\
& \left.+\int_{x_{2}}^{l_{1}} \frac{2}{\alpha} \tau_{m} e^{-2 \alpha\left(\left(x-x_{2}\right) / d\right)} d x\right\}=\frac{1}{E_{c}}\left\{x_{1}(\sigma\right. \\
& \left.-\frac{2 \tau_{0} x_{1}}{d}\right)+\Delta\left[\sigma-\frac{2 \tau_{0}}{d}\left(x_{1}+x_{2}\right)\right. \\
& \left.\left.+\frac{2\left(\tau_{m}-\tau_{0}\right) \Delta}{3 d}\right]+\left[-\frac{d \tau_{m}}{\alpha^{2}}\left(e^{-2 \alpha\left(\left(l_{1}-x_{2}\right) / d\right)}-1\right)\right]\right\} .
\end{aligned}
$$

In view of parameters in Table 1 , the three-dimensional fitting curve of (21) is calculated in MATLAB and plotted in Figure 10.

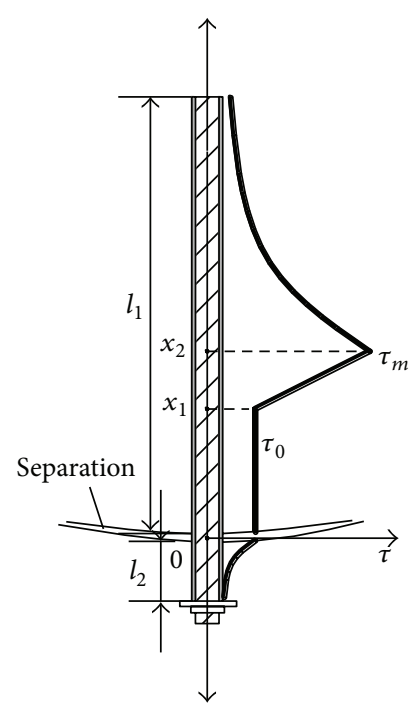

FIGURE 9: Shear stress distribution of the damaged interface when separation occurs near the loading end.

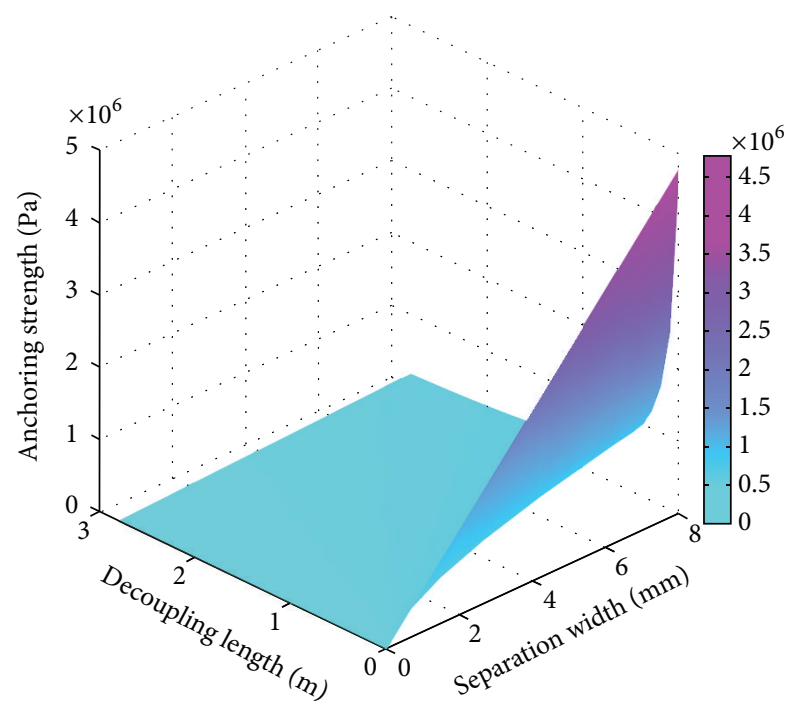

FIGURE 10: Relationship of the bolt support strength versus separation width and the bolt support strength versus decoupling length (the separation is located near the loading end).

Figure 10 shows that strata separations near the loading end and in the middle of the anchoring body have similar trends. A minor difference is that the ultimate support strength reaches $4.8 \mathrm{MPa}$ when separation occurs near the loading end; this value is greater than those in the previous two cases, being nearly twice the value of the second case $(2.39 \mathrm{MPa})$ in particular. This finding demonstrates that separation near the loading end, or near the surface of surrounding rock, only slightly disturbs the deeply bolted rock mass. Here, we introduce the deep-surface ratio, which is the ratio of the vertical displacement of a point deep within 


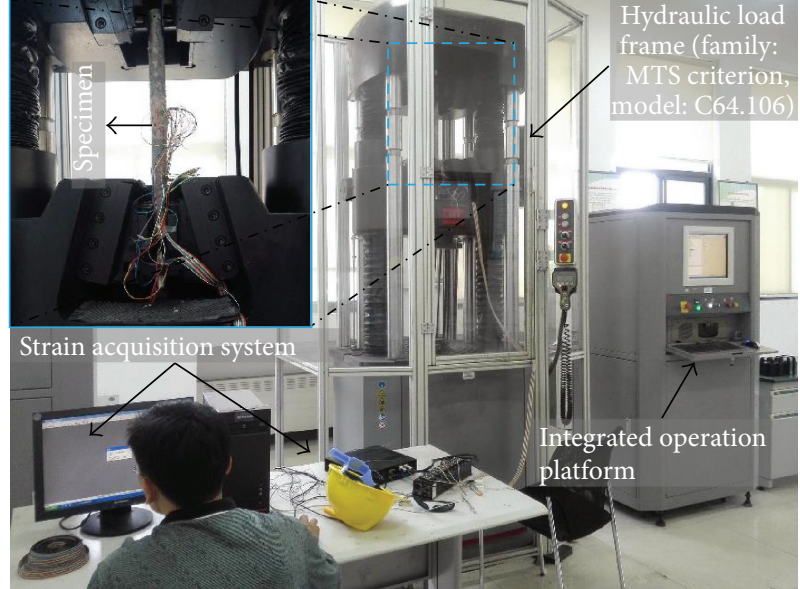

(a)
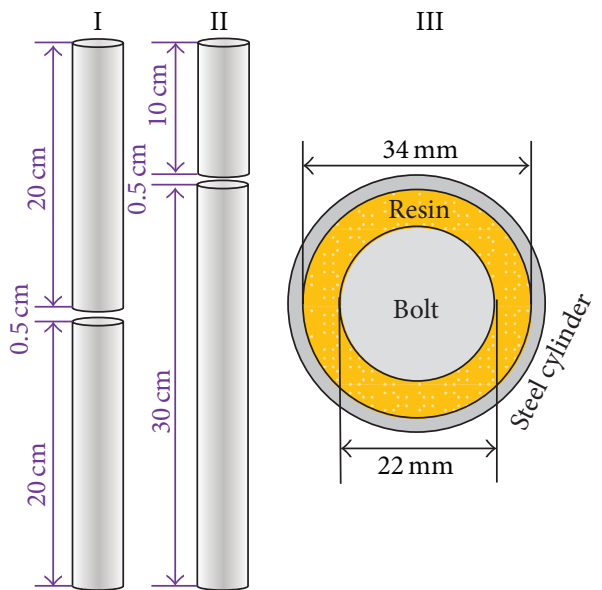

(b)

FIGURE 11: Experimental facilities and detailed parameters for the uniaxial bolt tension test. (a) Loading system and data acquisition facilities. (b) Detailed parameters for the steel cylinder and cross section of anchoring body; note that I represents separation occurring in the middle of the anchoring body, for which ten strain gauges were installed; II represents separation occurring at the free loading end, for which eleven strain gauges were installed; and III shows the cross-sectional dimensions of the specimen.

the rock to that of a surface point [33]. This ratio can be expressed as

$$
k_{x}=\frac{s_{x}}{s_{0}}
$$

where $k_{x}$ is the deep-surface ratio of the roof, $s_{x}$ is the vertical displacement of a point within the rock, $x$ is the distance from the point to the surface of surrounding rock (in $\mathrm{mm}$ ), and $s_{0}$ is the vertical displacement of the surface rock mass at the roof (in $\mathrm{mm}$ ).

The deep-surface ratio of the roof varies with the depth of the measured point in the rock mass. In this study, the separation location is the important factor; hence, three conditions can be defined:

Situation 1: separation occurs near the free loading end; $s_{c x} \approx s_{0}$, so $k_{c x}$ equals 1 .

Situation 2: separation occurs in the middle; $s_{b x}>s_{0}$, so $k_{b x}>1$.

Situation 3: separation occurs near the loading end; $s_{a x}>s_{0}$, so $k_{a x}>1$.

The deeper the measured point is, the smaller the displacement will be. Thus, $s_{a x}>s_{b x}>s_{c x}$, and $k_{a x}>$ $k_{b x}>k_{c x}=1$. Separation at any location will have a negative impact on the long-term stability of the anchoring system. Nevertheless, separation near the loading end can still provide stability and sufficient support strength to guarantee security, whereas separation in the middle provides less stability. Notably, separation near the free loading end is the least desirable, being unable to provide long-term stability to the surrounding rock or guarantee safety; thus, it should be avoided in underground engineering projects.

The analysis presented above considers one separation, but the distributions of shear stress have the same patterns if more than one separation is present. The final distribution is the sum of the individual cases. When more than one shear stress peak is present, the overall anchoring system will be less stable [34].

\section{Experimental Calibration}

To present a more intuitional explanation for the aforementioned analysis, this section describes an experiment conducted to simulate the relationship between strata separation and overall bolting stability.

4.1. Materials and Method. The experimental facilities and detailed parameters for the specimen are shown in Figure 11. We utilized a steel cylinder slotted with internal screw to simulate strata, and the rebar was a normal mine bolt with a diameter of $22 \mathrm{~mm}$. The steel cylinder parameters are shown in Figure 11(b), and the inner diameter and the total length are $34 \mathrm{~mm}$ and $40 \mathrm{~cm}$, respectively. As for the separation occurring at the free loading end, the upper cylinder with a length of $10 \mathrm{~cm}$ is used to simulate the strata above the separation, whereas the lower cylinder with a length of $30 \mathrm{~cm}$ is used to simulate the strata below the separation. The bolt was inserted into the cylinder and was fully coated by capsule resin, and the pull-out test was conducted after solidification of the resin.

In order to obtain accurate shear stress distribution along the bonding interface, we attached strain gauges on the interface before inserting the bolt. This way is reasonable because the relationship between strain and the stress is positively correlated. The bolt was longitudinally slotted to adapt the adhesion of strain gauges; the strain gauges used for separation occurring in the middle of the anchoring body were distributed as follows: ten strain gauges were attached along the bolt and five were placed on each side of separation 


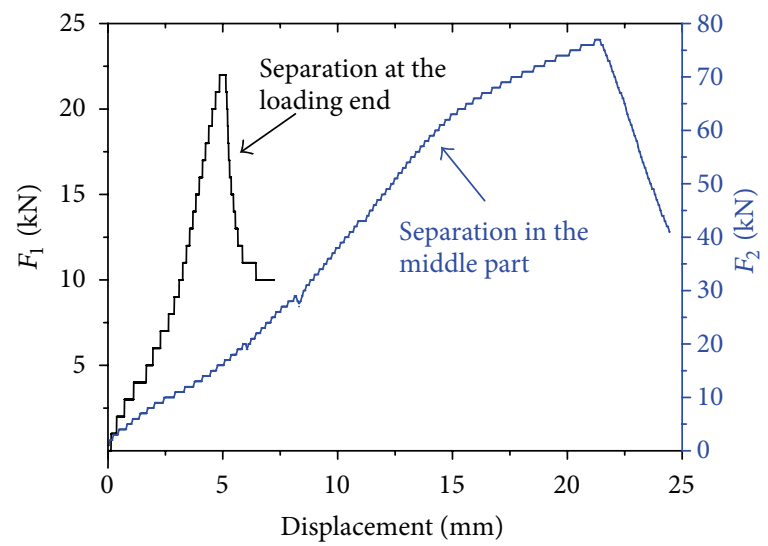

(a)

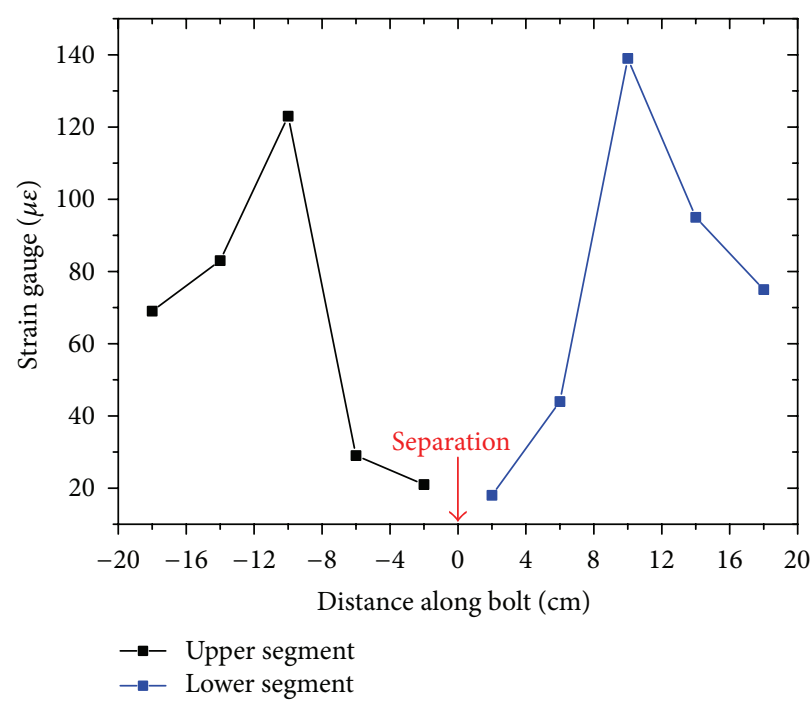

(c)

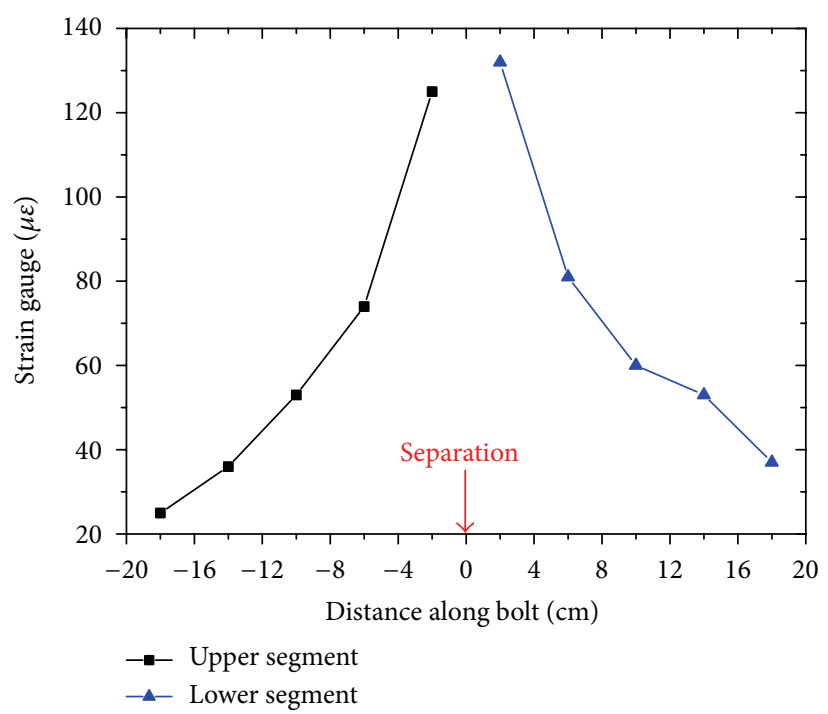

(b)

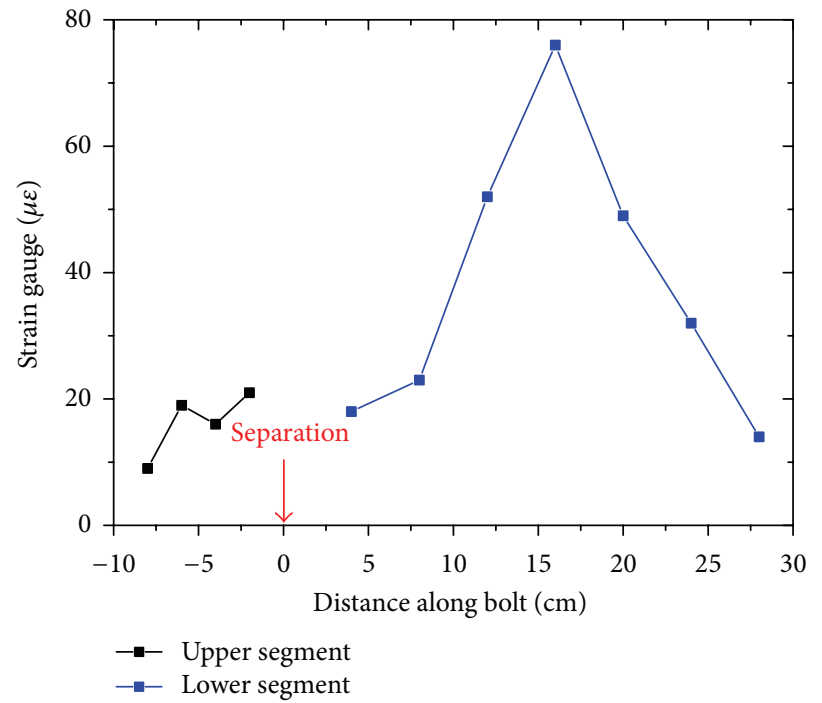

(d)

FIGURE 12: Experimental results for the anchoring body with separation at different locations. (a) Relationship between pulling force and pulling displacement. (b) Relationship between the strain and distance along the bolt when the interface is in its original intact state and the separation is located in the middle, (c) the interface is partly damaged and the separation is located in the middle, and (d) the interface is partly damaged and the separation is located at the loading end.

at distances of $2,6,10,14$, and $18 \mathrm{~cm}$ from the separation. The strain gauges used for separation occurring at the loading end were distributed as follows: total eleven strain gauges were adopted along the bolt, four of which were arranged on the shorter segment at 2, 4, 6, and $8 \mathrm{~cm}$ from the separation and seven of which were attached on the relatively longer segment at $4,8,12,16,20,24$, and $28 \mathrm{~cm}$ from the separation. The relatively closer interval between two adjacent strain gauges in shorter segment is to capture more characteristic points for obtaining the complete curves of strain distribution along the interface. The distribution of the strain gauges for separation occurring at the free loading end is essentially identical to that of the strain gauges for separation occurring at the loading end because the latter is the inverse of the former. The strain acquisition device was a TS 3866 distributed static resistance strain indicator (Yangzhou Taisi Electronics Co., Ltd.), and the sampling rate was $1 \mathrm{~Hz}$. The testing machine was produced by MTS Systems Corporation (Eden Prairie, MN, USA), and the loading rate was $3 \mathrm{~mm}$ per minute.

4.2. Results and Discussion. Results from a typical experimental calibration are shown in Figure 12. As illustrated in Figure 12(a), the overall peak bearing forces of anchoring body for separations occurring at the loading end and in the middle are $22 \mathrm{kN}$ and $77 \mathrm{kN}$, respectively. This finding confirms the results of the analysis presented in Section 3; 
namely, the damage near the loading end strongly influences the overall stability of the anchoring system and reduces the hanging effects of the bolt. Moreover, it can be seen that the maximum displacements that the bolts can sustain are also profoundly different, with the displacement of the bolt being 4 times greater in the case of separation in the middle than in the case of separation at the loading end. This finding indicates that premature failure of anchoring system may occur if strata separation occurs near the loading area.

Figure 12(b) shows a situation in which the separation occurs in the middle and the bonding interface is in its intact state. The general trend of the curve is strongly consistent with the conclusion that the shear stress along the interface decreases exponentially with increasing distance from the separation point; see Figure 4(b).

Based on the analysis in Section 3.2.2, a captured moment of strain distribution along the bolt is plotted in Figure 12(c) for the case in which the bonding interface is damaged due to excessive separation. A certain degree of deflection can be clearly observed by comparing this curve trend and that in Figure 7; nonetheless, the behavior is still somewhat consistent and variable. These results are thus capable of calibrating the former theoretical conclusions.

For separation at the loading end, Figure 12(d) outlines the general curve trend along both directions of separation. It must be noted that the interface was totally decoupled in the area ranging from -10 to $0 \mathrm{~cm}$ according to our observations of the final failure morphology of the specimen. This situation corresponds to the state illustrated in Figure 5.

These laboratory tests certainly differ from real field conditions for situations in which the separation is located at the loading end and free loading end. The dead weight of rock mass is ignored under laboratory conditions; hence, the stress distribution along both sides of the separation is mostly affected by the pulling force of the MTS machine, which maintains a constant loading speed, even when the interface damage occurs. In contrast, in the field, if separation occurs at the loading end and the interface damage is present, then the pulling force applied on the shorter segment mainly originates from the dead weight of the rock mass during this stage, and this force is too weak to isolate the interface bonding stress in most situations. The longer segment is then still partly encapsulated by resin and can pass through the aforementioned three stages under the relatively larger dead weight of the peripheral rock mass. This is why Figure 12(d) is markedly different from Figure 9.

\section{Conclusions}

(1) Layered strata occurrence is frequently seen in underground constructions; roof bolt supporting under the circumstance can suffer dynamic shock wave due to unexpected strata separation, which generally induces damage at the resin-rock interface and roof supporting failure. The damage progression is composed of elastic, slippage, and decoupling stages.

(2) A critical separation width can be defined if the bonding interface is undamaged, and the distribution of the shear stress is not sensitive to the separation location. Consequently, the stability of the anchoring system is not affected by the separation location under these conditions.

(3) If the interface is damaged, the distribution of shear stress is greatly affected by the separation location. The support strength increases exponentially with increasing separation width and simultaneously causes decoupling. However, at some point, the expansion of the decoupling will decrease the support strength. This decrease is significantly greater when the separation is located at the free loading end than when the separation is located at the loading end or in the middle. The elongation of the elastic section is small compared with the total increase of the separation width and can be ignored.

(4) The adverse effects of interfacial damage are mainly generated by the induced vibration of the anchoring force, which will eventually cause the bolting system to collapse. These effects increase dramatically if the damage extends from the free loading end to the loading end but can be moderated if the damage extends from the loading end to the free loading end.

(5) The experimental calibration testifies aforementioned theories. Research results of this study reveals a fact that even a tiny bolting defects can have a huge influence on the overall stability of bolting system; this kind of separation in layered strata should be avoided by applying relatively larger pretension force during installation process or by cement grouting in advance, which can tightly compact or bond the layered strata together to avoid subsequent inner separation from occurring.

\section{List of Symbols}

$d: \quad$ Borehole diameter

$k$ : $\quad$ Constant coefficient

$E_{r}: \quad$ Young's modulus of the rock mass

$E_{b}, E_{\mathrm{re}}$ : Young's modulus of the bolt $(b)$ and resin (re)

$d_{0}$ : Influence diameter around the bolt

$r_{b}, d_{b}: \quad$ Bolt radius and diameter

$l: \quad$ Total length of the anchoring body

$l_{1}$ : $\quad$ Length of the anchoring body above the separation

$l_{2}$ : Length of the anchoring body below the separation

A: $\quad$ Cross-sectional area of the anchoring body

$\left(0, x_{1}\right)$ : Decoupling section along the interface

$\left(x_{1}, x_{2}\right)$ : Slippage section along the interface

$\left(x_{2}, l\right): \quad$ Elastic section along the interface

$E_{c}$ : Composite Young's modulus of the bolt and resin

$k_{x}$ : Deep-surface ratio of the roof

$s_{x}$ : $\quad$ Vertical displacement of a point within the rock

$s_{0}$ : Vertical displacement of the surface rock mass at the roof. 


\section{Greek Symbols}

$\tau_{1}$ : Ultimate shear stress of the bolt-resin interface

$\tau_{2}$ : Ultimate shear stress of the resin-rock interface

$\tau(x)$ : Shear stress at $x$ along the resin-rock interface

$\tau$ : $\quad$ Shear stress at the loading end

$\sigma$ : Axial stress of the bolt at the loading point

$v_{r}, v_{\mathrm{re}}$ : Poisson's ratio of the rock mass and resin

$\tau_{0}$ : Residual shear stress of the decoupling section

$\tau_{m}$ : Ultimate shear stress that can be sustained by the intact interface

$\sigma_{b 0}$ : Maximum axial stress that can be sustained by the intact interface

$\delta_{\text {Jmax }}:$ Maximum width of the separation under an intact interface

$\delta_{1}$ : Width of the separation above the origin under an intact interface

$\delta_{2}$ : Width of the separation below the origin under an intact interface

$\delta_{J a}:$ Total width of the separation for separation at the free loading end

$\delta_{1 a}$ : Width of the separation above the origin for separation at the free loading end

$\delta_{2 a}$ : Width of the separation below the origin for separation at the free loading end

$\delta_{J b}$ : Total width of the separation for separation in the middle of the anchoring body

$\delta_{1 b}$ : Width of the separation above the origin for separation in the middle of the anchoring body

$\delta_{2 b}$ : Width of the separation below the origin for separation in the middle of the anchoring body

$\delta_{J c}$ : Total width of the separation for separation at the loading end

$\delta_{1 c}: \quad$ Width of the separation above the origin for separation at the loading end

$\delta_{2 c}: \quad$ Width of the separation below the origin for separation at the loading end.

\section{Conflict of Interests}

The authors declare that there is no conflict of interests regarding the publication of this paper.

\section{Acknowledgments}

Financial support for this paper was provided by the Fundamental Research Funds for the Central Universities under Contract no. 2014XT01 and the Program for Changjiang Scholars and Innovative Research Team in University under Contract no. IRT_14R55.

\section{References}

[1] S. S. Peng, "Topical areas of research needs in ground controla state of the art review on coal mine ground control," International Journal of Mining Science and Technology, vol. 25, no. 1, pp. 1-6, 2015.
[2] X. G. Zheng, J. B. Hua, N. Zhang, X. W. Feng, and L. Zhang, "Simulation of the load evolution of an anchoring system under a blasting impulse load using FLAC $3 \mathrm{D}$," Shock and Vibration, vol. 2015, Article ID 972720, 8 pages, 2015.

[3] T. B. Zhao, W. Y. Guo, Y. C. Yin, and Y. L. Tan, "Bolt pull-out tests of anchorage body under different loading rates," Shock and Vibration, vol. 2015, Article ID 121673, 8 pages, 2015.

[4] S. L. Lu, L. Tang, and X. A. Yang, Anchor Force and Anchoring Technology, China Coal Industry Publishing House, Beijing, China, 1998.

[5] Z. Y. Zheng and N. J. Huang, Resin Anchor Bolts and Capsules, China Coal Industry Publishing House, Beijing, China, 1983.

[6] A. Paul, A. P. Singh, J. Loui P, A. K. Singh, and M. Khandelwal, "Validation of RMR-based support design using roof bolts by numerical modeling for underground coal mine of Monnet Ispat, Raigarh, India-a case study," Arabian Journal of Geosciences, vol. 5, no. 6, pp. 1435-1448, 2012.

[7] C.-L. Han, N. Zhang, G.-C. Li, and J.-G. Kan, "Bed separation mechanism under sequential roof collapse condition in a gobside entry retaining," Journal of China University of Mining and Technology, vol. 41, no. 6, pp. 893-899, 2012.

[8] W. J. Ju, "Monitoring technology for rock bolting engineering," Journal of China Coal Society, vol. 25, supplement, pp. 58-61, 2000.

[9] C. Cao, T. Ren, and C. Chris, "Introducing aggregate into grouting material and its influence on load transfer of the rock bolting system," International Journal of Mining Science and Technology, vol. 24, no. 3, pp. 325-328, 2014.

[10] A. J. Hyett, W. F. Bawden, G. R. Macsporran, and M. Moosavi, "A constitutive law for bond failure of fully-grouted cable bolts using a modified hoek cell," International Journal of Rock Mechanics and Mining Sciences and, vol. 32, no. 1, pp. 11-36, 1995.

[11] Y. Cai, T. Esaki, and Y. J. Jiang, "A rock bolt and rock mass interaction model," International Journal of Rock Mechanics and Mining Sciences, vol. 41, no. 7, pp. 1055-1067, 2004.

[12] L. B. Martín, M. Tijani, F. Hadj-Hassen, and A. Noiret, "Assessment of the bolt-grout interface behaviour of fully grouted rockbolts from laboratory experiments under axial loads," International Journal of Rock Mechanics and Mining Sciences, vol. 63, pp. 50-61, 2013.

[13] F. F. Ren, Z. J. Yang, J. F. Chen, and W. W. Chen, "An analytical analysis of the full-range behaviour of grouted rockbolts based on a tri-linear bond-slip model," Construction and Building Materials, vol. 24, no. 3, pp. 361-370, 2010.

[14] P. K. Kaiser, S. Yazici, and J. Nosé, "Effect of stress change on the bond strength of fully grouted cables," International Journal of Rock Mechanics and Mining Sciences and, vol. 29, no. 3, pp. 293-306, 1992.

[15] W. Nie, Z. Y.Zhao, Y. J. Ning, and J. P. Sun, “Development of rock bolt elements in two-dimensional discontinuous deformation analysis," Rock Mechanics and Rock Engineering, vol. 47, no. 6, pp. 2157-2170, 2014.

[16] B. Benmokrane, A. Chennouf, and H. S. Mitri, "Laboratory evaluation of cement-based grouts and grouted rock anchors," International Journal of Rock Mechanics and Mining Sciences \& Geomechanics Abstracts, vol. 32, no. 7, pp. 633-642, 1995.

[17] M. Moosavi, A. Jafari, and A. Khosravi, "Bond of cement grouted reinforcing bars under constant radial pressure," Cement and Concrete Composites, vol. 27, no. 1, pp. 103-109, 2005. 
[18] I. W. Farmer, "Stress distribution along a resin grouted rock anchor," International Journal of Rock Mechanics and Mining Sciences and, vol. 12, no. 11, pp. 347-351, 1975.

[19] S.-M. He, J.-C. Tian, and J.-T. Zhou, "Study on load transfer of bond prestressed anchor rope," Chinese Journal of Rock Mechanics and Engineering, vol. 25, no. 1, pp. 117-121, 2006.

[20] C. A. You, Y. B. Zhan, Q. Y. Liu, L. L. Sun, and K. B. Wang, "Shear lag-debonding model for anchorage section of prestressed anchor cable," Chinese Journal of Rock Mechanics and Engineering, vol. 32, no. 4, pp. 800-806, 2013.

[21] C. X. Zhu, X. Chang, Y. D. Men, and X. L. Luo, "Modeling of grout crack of rockbolt grouted system," International Journal of Mining Science and Technology, vol. 25, no. 1, pp. 73-77, 2015.

[22] C. C. Li, "A practical problem with threaded rebar bolts in reinforcing largely deformed rock masses," Rock Mechanics and Rock Engineering, vol. 40, no. 5, pp. 519-524, 2007.

[23] H. Jalalifar and N. Aziz, "Analytical behaviour of bolt-joint intersection under lateral loading conditions," Rock Mechanics and Rock Engineering, vol. 43, no. 1, pp. 89-94, 2010.

[24] S.-H. Chen, S. Qiang, S.-F. Chen, and P. Egger, "Composite element model of the fully grouted rock bolt," Rock Mechanics and Rock Engineering, vol. 37, no. 3, pp. 193-212, 2004.

[25] A. J. Hyett, M. Moosavi, and W. F. Bawden, "Load distribution along fully grouted bolts, with emphasis on cable bolt reinforcement," International Journal for Numerical and Analytical Methods in Geomechanics, vol. 20, no. 7, pp. 517-544, 1996.

[26] S. M. He and X. P. Li, "Study on mechanism of prestressed anchor bolt," Chinese Journal of Rock Mechanics and Engineering, vol. 25, no. 9, pp. 1876-1880, 2006.

[27] C. C. Li, "Field observations of rock bolts in high stress rock masses," Rock Mechanics and Rock Engineering, vol. 43, no. 4, pp. 491-496, 2010.

[28] L. A. Panek, Principles of Reinforcing Bedded Mine Roof with Bolts, US Department of the Interior, Bureau of Mines, 1956.

[29] C. Li and B. Stillborg, "Analytical models for rock bolts," International Journal of Rock Mechanics and Mining Sciences, vol. 36, no. 8, pp. 1013-1029, 1999.

[30] B. Stillborg, Professional Users Handbook for Rock Bolting, Trans Tech Publications, Clausthal-Zellerfelt, Germany, 1994.

[31] W. F. Bawden, A. J. Hyett, and P. Lausch, "An experimental procedure for the in situ testing of cable bolts," International Journal of Rock Mechanics and Mining Sciences and, vol. 29, no. 5, pp. 525-533, 1992.

[32] X. G. Zheng, Evolutionary Mechanism of Bolt's(Cable's) Lift Anchoring Force and Surrounding Rock Controlling Technology of Roadway in Coalmine, China University of Mining and Technology, Xuzhou, China, 2013.

[33] S. L. Lu, G. B. Fu, and L. Tang, "Regularity of deformation of rocks around roadway under mining influence and change of rockbolt resistance," Journal of China University of Mining and Technology, vol. 19, no. 4, pp. 201-203, 1999.

[34] F. Bjornfot and O. Stephansson, "Interaction of grouted rock bolts and hard rock masses at variable loading in a test drift of the Kiirunavaara Mine, Sweden," in Proceedings of the International Symposium on Rock Bolting, pp. 377-395, Balkema, Rotterdam, The Netherlands, 1984. 


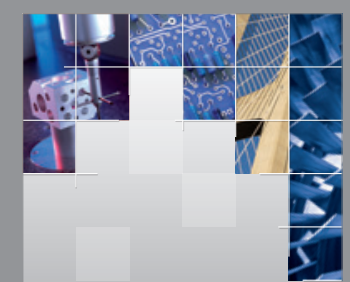

\section{Enfincering}
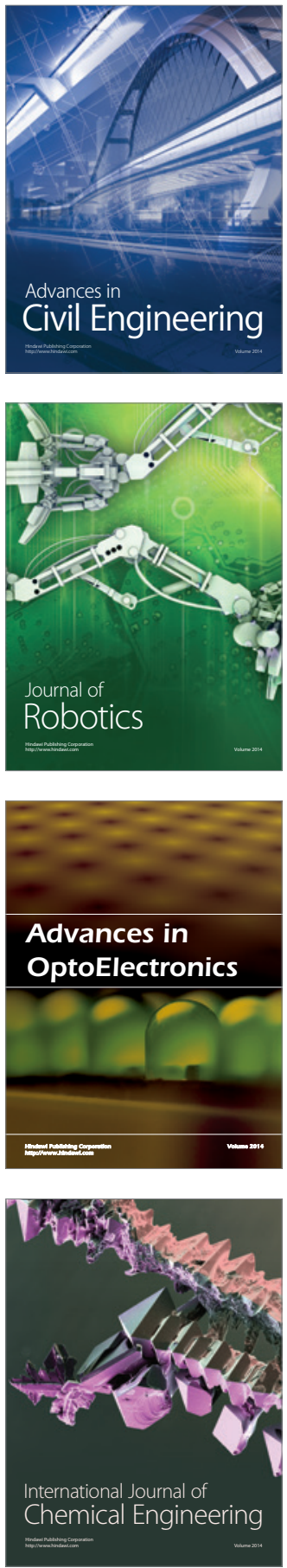

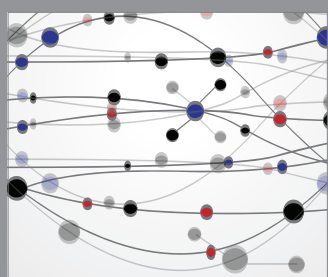

The Scientific World Journal

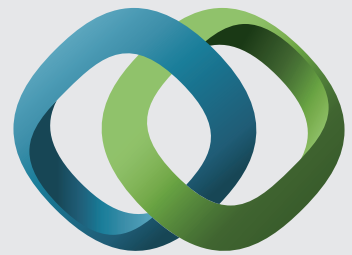

\section{Hindawi}

Submit your manuscripts at

http://www.hindawi.com
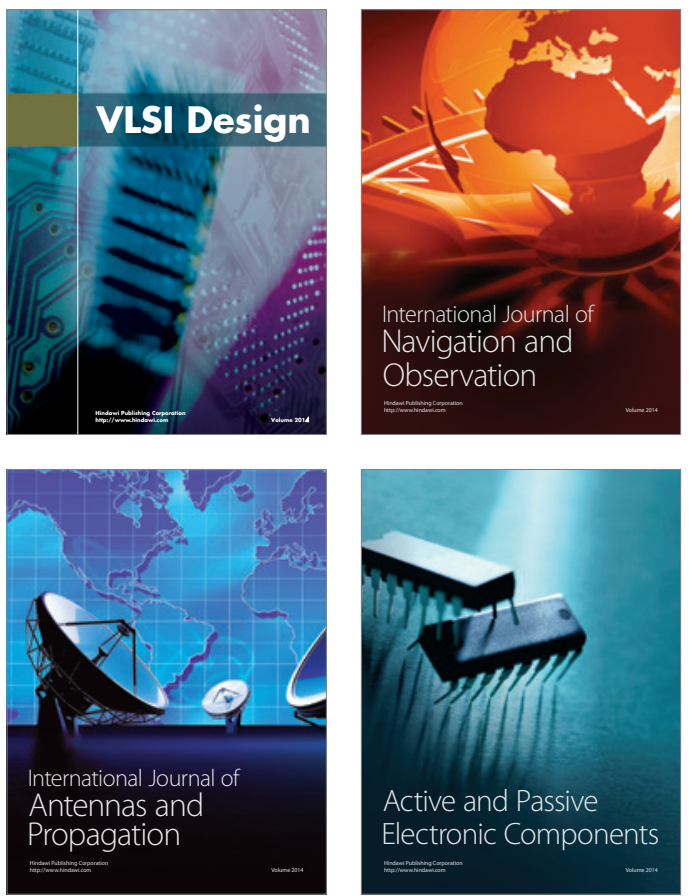
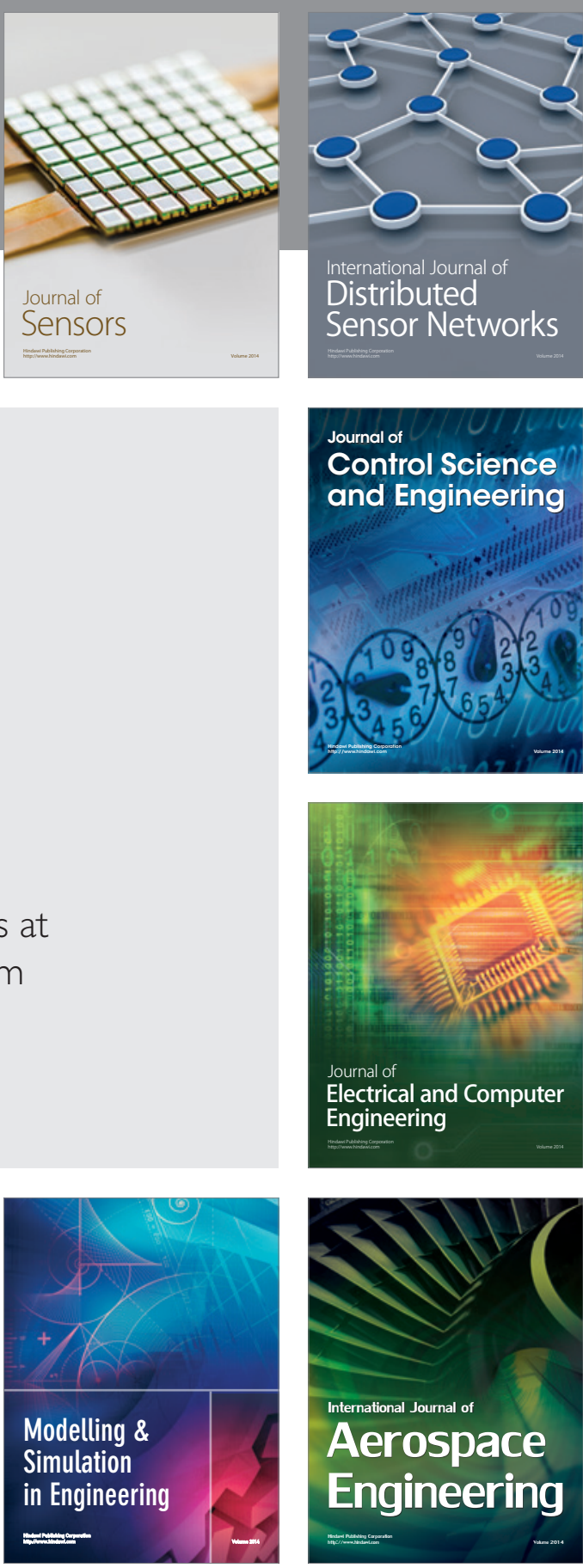

International Journal of

Distributed

Sensor Networks

Journal of

Control Science

and Engineering
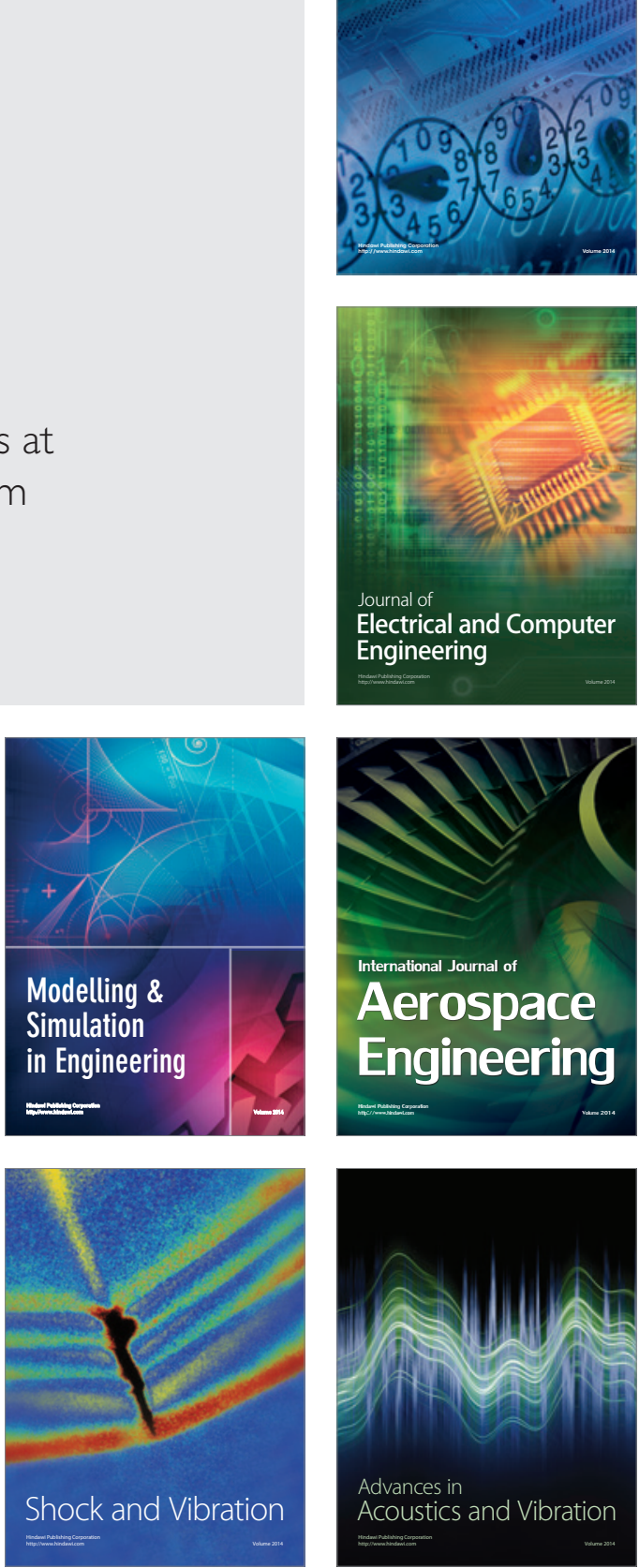